\title{
The Impact of Anastomosis Location in Patients with Lower Thoracic Esophageal Squamous Cell Carcinoma: A Retrospective Observational Study
}

\section{Wenyu Zhai}

Sun Yat-sen University Cancer Center

\section{Shenshen Fu}

Guangzhou First People's Hospital

\section{Xiaoqiang Li}

Peking University Shenzhen Hospital

\section{Fangfang Duan}

Sun Yat-sen University Cancer Center

\section{Hongying Liao}

Sun Yat-sen University Sixth Affiliated Hospital

Junye Wang ( $\sigma_{\text {jywangmed@163.com ) }}$

Sun Yat-sen University Cancer Center

\section{Research Article}

Keywords: ESCC, Anastomosis, Prognosis

Posted Date: November 8th, 2021

DOI: https://doi.org/10.21203/rs.3.rs-1029546/v1

License: (1) This work is licensed under a Creative Commons Attribution 4.0 International License. Read Full License 


\section{Abstract}

\section{Background}

Several kinds of anastomoses with varying locations that can be performed after the surgical resection of lower thoracic esophageal squamous cell carcinoma. In this study, we evaluated the prognostic impact of anastomosis locations in these patients who underwent radical esophagectomy.

\section{Methods}

Lower thoracic esophageal squamous cell carcinoma patients which underwent radical esophagectomy and confirmed as microscopically complete resection were retrospectively enrolled. Anastomoses below the aortic arch or below the azygos arch were defined as low anastomosis. Other anastomoses were defined as high anastomosis. Overall survival of these two kinds of anastomoses were analyzed using the log-rank test and Cox regression model.

\section{Results}

Of the 781 patients enrolled, 196 and 585 were classified as the low anastomosis and high anastomosis groups, respectively. Overall, the survival time in low anastomosis group (median 0S, 36.1 versus 65.4; $\mathrm{P}=0.01$ ) was shorter than high anastomosis group but no statistical difference was observed in multivariate analysis $(P=0.195)$. Again, no significant difference in survival between low anastomosis and high anastomosis group (median OS, 140.9 versus 124.8; $\mathrm{P}=0.345$ ) were observed in $\mathrm{pT} 1-\mathrm{T} 2$ subgroup. In pT3-T4 subgroups, patients with low anastomosis group had significantly poorer survival that those with high anastomosis (median $\mathrm{OS}, 27.1$ versus 42.9, $\mathrm{P}=0.003$ ), even after controlling for other confounders $(P=0.026)$. Notably, the impact of anastomosis location on long-term survival in pT3-4 patients was not significantly modified by nodal status. The internal validation of patients undergoing Sweet approach shown that pT3-T4 patients with high anastomosis had survival advantages (adjusted $\mathrm{HR}=0.711,95 \% \mathrm{Cl}, 0.6010 .990, \mathrm{P}=0.041$ )

\section{Conclusions}

For lower thoracic esophageal squamous cell carcinoma with declared T3-4 status, low anastomosis is associated with worse prognosis and should be avoided.

\section{Background}

Esophageal cancer (EC) is the sixth most prevalent cancer worldwide and China accounts for more than half of the new cases and death in the world (1-3). EC can be subdivided into two main histological subtypes, namely, squamous cell carcinomas (SCC) and adenocarcinomas (AC). Esophageal squamous cell carcinoma (ESCC) is the major histological subtype in China $(4,5)$. Although multimodality treatment is the mainstay treatment for operable ESCC, surgery remains the pillar part of the multimodality treatment (6). 
The surgical procedures for EC include esophagectomy and lymphadenectomy. An extended esophagectomy with negative margin is critical to guarantee long-term survival after surgery. For ESCC with middle or upper thoracic location, anastomosis in the upper thorax or in the neck is commonly performed to guarantee sufficient margin distance; different to lower thoracic ESCC which has its own characteristics. First, downward lymphatic drainage is more frequent in lower thoracic ESCC (7). Second, the primary tumor of lower thoracic ESCC is relatively further away from the trachea and the available space for performing anastomosis is also larger than those ESCC located at the upper or middle thorax; which reduce the rate of local invasion and make surgery easier. These characteristics allow more anastomosis choices. Anastomosis below the aortic or azygos arch is a lesser invasive approach for limited esophagectomy, which is widely performed in surgical setting (8). However, the prognostic impact of anastomosis location is still unclear. Therefore, to address this unresolved issue we perform this retrospective study.

\section{Methods}

\section{Patients}

This study was approved by the Institutional Review Board of Sun Yat-sen University Cancer Center. In this study, we retrospectively screened for patients with low thoracic ESCC who underwent radical esophagectomy in the thoracic surgery department of Sun Yat-sen University Cancer Center between January 2000 and December 2012. Inclusion criteria included: (1) confirmatory pathological diagnosis as lower thoracic ESCC; (2) pathologic T status of T1, T2, T3, or T4a; (3) absence of distant metastasis; (4) underwent radical esophagectomy with confirmed microscopic clear margins of resection (R0); (5) did not received any form of neoadjuvant therapy. All patients were staged according to the TNM staging criteria of the 8th American joint Committee on cancer (AJCC) staging system.

\section{Surgical Approach And Fellow-up}

In this study, esophagectomy was achieved through three thoracic approaches, including the Ivor-Lewis, McKeown, and Sweet approach. Details of surgical procedure have been described previously $(9,10)$. In this research, we defined anastomosis below the aortic (left thoracotomy) and azygos arch (right thoracotomy) as low anastomosis (LA). Other kinds of anastomoses were defined as high anastomosis $(H A)$. Follow-up were performed every 3 months in the first two years, every 6 months until 5 years and once a year thereafter. Surgeons would choose Upper gastrointestinal contrast or ultrasonography or computed tomography scan as needed.

\section{Statistical analysis}

We used t-test to compare quantitative data and Pearson's $\chi 2$ or Fisher's exact test to compare categorical data between two groups. The overall survival was estimated using the Kaplan-Meier method 
and compared using the log-rank test. Cox proportional hazards regression model was constructed to identify prognostic factors and calculate adjusted hazard ratio (HR). Predictors assessed in this study included: age, sex, anastomosis location, pathologic T status, pathologic $N$ status, pathologic $\mathrm{G}$ class, operative approach, and number of resected nodes. All factors with $\mathrm{P}<0.1$ in univariate survival analysis were enrolled in multivariate analysis. Statistical significance was reached when $P$ value $<0.05$, all hypotheses were two-sided. Statistical analysis to identify risk characteristics were performed using the SPSS 22.0 software package (SPSS, Inc., Chicago, IL).

\section{Results}

\section{Patient's characteristics}

A total of 781 patients were enrolled, comprising of 667 male and 114 female patients. The average age of the patients was 59 years (range, 32-84 years). Of the 646 patients who underwent left thoracotomy approach, 193 patients had anastomosis below the aortic. 138 patients underwent right thoracotomy of whom 3 had anastomosis below the azygos arch.

Overall, 196 patients were classified in the low anastomosis (LA) group and 585 patients in the high anastomosis (HA) group. The median number of resected lymph nodes of the entire study cohort was 16 (interquartile range, 9 to 25). The baseline characteristics of the patients are shown in Table1. Patients in the HA group had a significantly greater number of resected lymph nodes (median, 13 versus 16; $P<0.001)$ and had a notably higher percentage of patients who underwent right thoracotomy approach $(22.6 \%$ versus $1.5 \%, P<0.001)$. There was no significant difference in age, sex, pathologic $T$ status, pathologic $\mathrm{N}$ status and pathologic $\mathrm{G}$ class between the two anastomotic groups. 
Table 1

Patient Characteristics

\begin{tabular}{|c|c|c|c|}
\hline Characteristic & $\begin{array}{l}\text { HA group } \\
n=585\end{array}$ & $\begin{array}{l}\text { LA group } \\
n=196\end{array}$ & $P$ value \\
\hline Age & $57.97 \pm 9.01$ & $61.37 \pm 9.34$ & 0.100 \\
\hline Sex & & & 0.428 \\
\hline Male & $503(86.0)$ & $164(83.7)$ & \\
\hline Female & $82(14.9)$ & $32(16.3)$ & \\
\hline pT stage & & & 0.071 \\
\hline T1 & $45(7.6)$ & $14(7.2)$ & \\
\hline $\mathrm{T} 2$ & $146(25.0)$ & $32(16.3)$ & \\
\hline T3 & $380(65.0)$ & $146(74.5)$ & \\
\hline $\mathrm{T} 4 \mathrm{a}$ & $14(2.4)$ & $4(2.0)$ & \\
\hline pN stage & & & 0.283 \\
\hline NO & $256(43.8)$ & $94(48)$ & \\
\hline N1 & $212(36.2)$ & $73(37.2)$ & \\
\hline N2 & $85(14.5)$ & $18(9.2)$ & \\
\hline N3 & $32(5.5)$ & $11(5.6)$ & \\
\hline G stage & & & 0.717 \\
\hline G1 & $134(22.9)$ & $45(23.0)$ & \\
\hline G2 & $306(52.3)$ & $97(49.5)$ & \\
\hline G3 & $145(24.8)$ & $54(27.5)$ & \\
\hline Amount of resected nodes & $19.23 \pm 12.93$ & $13.96 \pm 9.65$ & $<0.001$ \\
\hline Surgical approach & & & $<0.001$ \\
\hline Left-thoracotomy & $453(77.4)$ & $193(98.5)$ & \\
\hline Right-thoracotomy & $132(22.6)$ & $3(1.5)$ & \\
\hline
\end{tabular}

\section{Survival Analysis}

The median overall survival time for the entire cohort was 54.9 months. In HA and LA group, the 1-, 3-, and 5 -year OS rate was $84.9 \%, 59.4 \%$, and $51.4 \%$, respectively and was $84.3 \%, 50.3 \%$, and $42.8 \%$, respectively. 
The median survival time of patients in the HA group was significantly longer than those in the LA group (65.4 versus 36.1; Log Rank $P=0.01$ ) (Fig. 1A). However, the prognostic impact of anastomotic location did not show any statistical difference in multivariate analysis after controlling for other confounders identified from univariate analysis $(\mathrm{HR}=0.860,95 \% \mathrm{Cl}, 0.6891 .078, P=0.195)$, while gender, age, pathologic $\mathrm{T}$ status, pathologic $\mathrm{N}$ status, operative approach, and number of resected nodes were the independent prognostic factors in multivariate analysis. (Table 2). 
Table 2

Univariate and multivariate analysis for the entire patients and pT3-4 patients

\begin{tabular}{lllllllll} 
factors & \multicolumn{3}{l}{ univariate analysis } & \multicolumn{5}{l}{ multivariate analysis } \\
\cline { 2 - 9 } & HR & $95 \% \mathrm{Cl}$ & & $\boldsymbol{P}$ & HR & $95 \% \mathrm{Cl}$ & $\boldsymbol{P}$ \\
\hline For the entire cohort & & & & & & & \\
\hline gender & 0.618 & 0.456 & 0.837 & 0.002 & 0.663 & 0.487 & 0.904 & 0.009 \\
\hline age & 1.018 & 1.007 & 1.029 & 0.001 & 1.018 & 1.007 & 1.028 & 0.001 \\
\hline operative approach & 0.669 & 0.505 & 0.887 & 0.005 & 0.726 & 0.540 & 0.977 & 0.034 \\
\hline T & & & & & & & & \\
\hline T1 & Ref & & & & Ref & & & \\
\hline T2 & 1.834 & 1.090 & 3.088 & 0.022 & 1.691 & 1.001 & 2.856 & 0.049 \\
\hline T3 & 2.837 & 1.740 & 4.627 & $<0.001$ & 2.151 & 1307 & 3.543 & 0.003 \\
\hline T4a & 7.710 & 3.025 & 15.144 & $<0.001$ & 3.831 & 1.905 & 7.704 & $<0.001$ \\
\hline N & & & & & & & & \\
\hline N0 & Ref & & & & Ref & & & \\
\hline N1 & 1.984 & 1.582 & 2.489 & $<0.001$ & 1.783 & 1.411 & 2.258 & $<0.001$ \\
\hline N2 & 3.385 & 2.566 & 4.466 & $<0.001$ & 3.093 & 2.324 & 4.117 & $<0.001$ \\
\hline N3 & 5.385 & 3.722 & 7.793 & $<0.001$ & 4.251 & 2.872 & 6.293 & $<0.001$ \\
\hline number of resected & 0.989 & 0,981 & 0.997 & 0.01 & 0.988 & 0.979 & 0.997 & 0.006 \\
nodes & & & & & & & & \\
\hline
\end{tabular}

\section{For patients with T3-4} status

$\begin{array}{lllllllll}\text { age } & 1.019 & 1.006 & 1.031 & 0.003 & 1.014 & 1.002 & 1.026 & 0.020 \\ \text { anastomosis location } & 0.689 & 0.496 & 0.956 & 0.026 & 0.726 & 0.597 & 0.972 & 0.026\end{array}$

\section{T}

T3

Ref

Ref

\begin{tabular}{lllllllll} 
T4a & 2.649 & 1.622 & 4.326 & $<0.001$ & 2.018 & 1.220 & 3.338 & 0.006 \\
N & & & & & & & & \\
N0 & Ref & & & & Ref & & & \\
N1 & 1.889 & 1.439 & 2.480 & $<0.001$ & 1.910 & 1.455 & 2.508 & 0.000 \\
N2 & 3.047 & 2.192 & 4.235 & $<0.001$ & 3.148 & 2.259 & 4.388 & 0.000 \\
\hline
\end{tabular}




\begin{tabular}{|c|c|c|c|c|c|c|c|c|}
\hline \multirow[t]{2}{*}{ factors } & \multicolumn{4}{|c|}{ univariate analysis } & \multicolumn{4}{|c|}{ multivariate analysis } \\
\hline & HR & $95 \% \mathrm{Cl}$ & & $P$ & HR & $95 \% \mathrm{Cl}$ & & $P$ \\
\hline N3 & 4.475 & 2.971 & 6.470 & $<0.001$ & 4.346 & 2.845 & 6.616 & 0.000 \\
\hline $\begin{array}{l}\text { number of resected } \\
\text { nodes }\end{array}$ & 0.984 & 0,975 & 0.993 & 0.001 & 0.984 & 0.974 & 0.993 & 0.001 \\
\hline
\end{tabular}

Then, we calculated the adjusted HR value of anastomosis location at different T stages for HA versus LA. Our findings showed that the HR of LA was higher than that of HA in patients with pT3-4 status (pT3: adjusted HR = 1.459; pT4: adjusted HR = 1.065) but lower than HA in patients with pT1-2 status (pT1: adjusted HR $=0.911 ;$ pT2: adjusted HR $=0.802$ ) (Fig. 1B). Therefore, patients from both anatomic groups were then subdivided into two different T-stage subgroups, namely the pT1-T2 group and PT3-T4 group.

For the entire PT1-T2 subgroup, observed median survival time was 140.9 months. The prognosis of patients in the LA group was comparable to those in the HA group (median OS, 140.9 versus 124.8; Log Rank $P=0.345$ ) (Fig. 1C). Similar results were observed in subgroup stratified by nodal status ( $\mathrm{N}$-: $\mathrm{HR}=1.366,95 \% \mathrm{Cl}, 0.6662 .800, \mathrm{P}=0.394 ; \mathrm{N}+\mathrm{HR}=2.294,95 \% \mathrm{Cl}, 0.727$ 7.242, $\mathrm{P}=0.157$ ) (Supplementary Fig. $1 A$ and $B)$.

For the pT3-T4 subgroup, the median survival time was 34.7 months. Patients in the HA group had significantly better survival outcomes as compared with patients in the LA group (median OS 42.9 versus 27.1; Log Rank $P=0.003$ ) (Fig. 1D). This difference remained significant even after controlling for other confounders (adjusted $\mathrm{HR}=0.726,95 \% \mathrm{Cl}, 0.5970 .972, P=0.026$ ) (Table 2). Similar results were observed in subgroup stratified by nodal status (Fig. $1 \mathrm{E}$ and $\mathrm{F}$ ) ( $\mathrm{N}$-: adjusted $\mathrm{HR}=0.582,95 \% \mathrm{Cl}, 0.3690 .920$, $P=0.021 ; \mathrm{N}+$ : adjusted $\mathrm{HR}=0.567,95 \% \mathrm{Cl}, 0.3230 .995, P=0.048)$.

Taking into account the bias associated with the surgical approach, we performed an internal validation of patients undergoing left thoracotomy approach. As shown in Figure 2, though anastomosis location did not affect the outcome of patients underwent Sweet approach (median OS 51.9 versus 38.0; Log Rank $P=0.067$ ) (Fig. 2A) as well as patients underwent Sweet approach in $\mathrm{pT} 1-\mathrm{T} 2$ subgroup (median OS 95.1 versus 140.8; Log Rank $P=0.284$ ) (Fig. 2B), patients underwent Sweet approach in pT3-T4 subgroup with high anastomosis had a better OS compared with patients with low anastomosis (median OS 27.1 versus 25.1; Log Rank $P=0.024$ ) (Fig. $2 \mathrm{C}$ ). In multivariate analysis, patients underwent Sweet approach in pT3-T4 subgroup with high anastomosis had survival advantages while controlling for other confounders (adjusted $\mathrm{HR}=0.711,95 \% \mathrm{Cl}, 0.6010 .990, P=0.041$ ) (Table 3) 
Table 3

Univariate and multivariate analysis for the entire patients and pT3-4 patients with Sweet approach. factors

\section{univariate analysis}

$\mathrm{HR} \quad 95 \% \mathrm{Cl}$ multivariate analysis

$\begin{array}{llll}P & \text { HR } \quad 95 \% \mathrm{Cl} \quad P\end{array}$

\section{For the entire cohort}

\begin{tabular}{lllllllll} 
gender & 0.660 & 0.482 & 0.902 & 0.009 & 0.709 & 0.515 & 0.974 & 0.034 \\
\hline age & 1.019 & 1.008 & 1.030 & 0.001 & 1.020 & 1.009 & 1.032 & $<0.001$ \\
\hline T & & & & & & & & \\
\hline T1 & Ref & & & & Ref & & & \\
\hline T2 & 1.712 & 0.982 & 2.987 & 0.058 & 1.366 & 0.781 & 2.391 & 0.274 \\
\hline T3 & 2.644 & 1.570 & 4.452 & $<0.001$ & 1.865 & 1.036 & 3.005 & 0.036 \\
\hline T4a & 7. & 3.444 & 14.520 & $<0.001$ & 2.800 & 1.326 & 5.915 & 0.007 \\
\hline N & 720 & & & & & & & \\
\hline N0 & & & & & & & & \\
\hline N1 & Ref & & & & & & & \\
\hline N2 & 2.089 & 1.640 & 2.661 & $<0.001$ & 1.911 & 1.488 & 2.455 & $<0.001$ \\
\hline N3 & 3.445 & 2.544 & 4.665 & $<0.001$ & 3.036 & 2.243 & 4.178 & $<0.001$ \\
\hline
\end{tabular}

\section{For patients with T3-4}

status

\begin{tabular}{lllllllll} 
age & 1.020 & 1.007 & 1.033 & 0.002 & 1.017 & 1.004 & 1.030 & 0.008 \\
\hline anastomosis location & 0.755 & 0.592 & 0.964 & 0.024 & 0.711 & 0.601 & 0.990 & 0.041 \\
\hline T & & & & & & & & \\
\hline T3 & Ref & & & & Ref & & & \\
\hline T4a & 2.632 & 1.560 & 4.440 & $<0.001$ & 1.766 & 1.029 & 3.031 & 0.039 \\
\hline N & & & & & & & & \\
\hline N0 & Ref & & & & Ref & & & \\
\hline N1 & 2.053 & 1.539 & 2.738 & $<0.001$ & 2.060 & 1.544 & 2.750 & $<0.001$ \\
\hline N2 & 3.154 & 2.205 & 4.511 & $<0.001$ & 3.102 & 2.162 & 4.452 & $<0.001$ \\
\hline N3 & 4.836 & 3.128 & 7.477 & $<0.001$ & 4.338 & 2.769 & 6.797 & $<0.001$ \\
\hline
\end{tabular}




\section{Discussion}

Lower thoracic ESCC has its own spread, anatomy, space relation and prognosis characteristics which make it a special type of esophageal cancer. Until now, there has been no consensus on the extent of esophageal resection. Although HA and LA have been widely applied in clinics, comparison between these anastomosis locations on long-term survival is still unclear. Based on our results, LA is associated with poor prognosis in lower thoracic ESCC with PT3-T4 status and should be avoided for this cohort.

In our study, we defined cervical anastomosis and high intrathoracic anastomosis as high anastomosis (HA) and sub-aortic anastomosis and anastomosis below the azygos arch as low anastomosis (LA). The basis of this classification was based on from findings of our pilot study which suggested that the prognosis of cervical anastomosis and high intrathoracic anastomosis was similar both in the entire cohort or subgroup analysis stratified by pT status (data not shown). Manabu Okuyama et al, in their randomized controlled trial reported that patients with cervical anastomosis and high intrathoracic anastomosis had similar surgical outcomes (11).

In this study, we firstly evaluated the impact of anastomosis choice in this entire cohort. Although LA was found to be correlated with shorter survival, it lacked statistical significance after controlling for other confounders. Then, we evaluated the impact of anastomosis choice in subgroup analysis stratified by pT status. We found that for patients with T1-2 status, the prognosis achieved by LA was similar to HA (median OS, 140.9 versus $124.8 ; P=0.345$ by log-rank test), whereas for patients with T3-4 status, HA was associated with better outcome than LA, even after controlling for other confounders adjusted $H R=0.726$, $95 \% \mathrm{Cl}, 0.5970 .972, \mathrm{P}=0.026)$. Furthermore, the survival advantage of $\mathrm{HA}$ was not significantly modified by nodal status $(\mathrm{N}-$ : adjusted $\mathrm{HR}=0.582,95 \% \mathrm{Cl}, 0.3690 .920, \mathrm{P}=0.021 ; \mathrm{N}+$ : adjusted $\mathrm{HR}=0.567,95 \% \mathrm{Cl}$, $0.3230 .995, P=0.048$ ). Therefore, the detrimental impact of LA might be concentrated on patients with advanced primary tumor stage.

For this issue, although the underlying mechanism is still unclear, it might be associated to two reasons. First, the existence of second multiple primary esophageal squamous cell carcinomas (SMPESCC). According to a previous study, SMPESCC is a common phenomenon in ESCC with the general incidence of $0.1-10 \%(12-14)$. A previous study reported that lower esophagus was the most common segment in which SMPESCC occurs (54.7\%) (15). In addition, Predrag Pesko et al, in their study found out locally advanced patients were more likely suffered from multiple ESCC (16). This incidence would be even higher when the tumor is low thoracic location and locally advanced. Therefore, lower thoracic ESCC patients with T3-4 status might require a more extended esophagectomy to clear potential SMPESCC. Second, as is well known, lymph vessels exist in all layers of esophageal expect the epithelium and outer membrane (17). When the tumor invades deeper layers, the incidence of lymphatic metastasis or micrometastasis would increase. Thus, for locally advanced ESCC, it would be beneficial to perform an extended esophagectomy.

Debate between right and left transthoracic approach for resectable ESCC has long been a hot topic for a long time. Recently, a series of studies have shown that the right thoracic approach was superior to left 
thoracic approach on extensive lymphadenectomy, especially in the upper mediastinum, which was critical for more accurate staging and long-term survival $(10,18)$. In this study, the proportion of patients undergoing HA was significantly higher in the right-thoracotomy group (97.8\% versus $70.1 \%$ ). The fact that extensive esophagectomy is more common in right thoracic approach might be another explanation for survival advantage of right thoracic approach.

Based on our results, LA for lower thoracic ESCC staged as pT3-4 may not be appropriate. For pT1-2 patients, low anastomosis should still be cautiously adopted due to its potentially detrimental impact on eliminating micrometastasis. Routine EUS examination before operation is greatly help for treatment decision (19).

There are some limitations should be considered in this study. First, this is a single-institution retrospective study. Second, we did not perform an external validation to validate the findings. Third, patients with neoadjuvant treatment were not included. Therefore, further validation from multi-center database is needed and meanwhile, the findings from this study should be cautiously interpreted.

\section{Conclusion}

For pT3-4 lower thoracic ESCC, LA was associated with worse prognosis and other alternatives should be considered.

\section{Abbreviations}

ESCC

esophageal squamous cell carcinoma

LA

low anastomosis

$\mathrm{HA}$

high anastomosis

OS

overall survival

EC

esophageal cancer

SCC

squamous cell carcinomas

AC

adenocarcinomas

SPSS

Statistical Product and Service Solutions

HR

hazard ratio 
nodes

SMPESCC

second multiple primary esophageal squamous cell carcinomas

\section{Declarations}

Ethics approval and consent to participate

This study was approved by the Institutional Review Board of Sun Yat-sen University Cancer Center.

Consent for publication

All patients enrolled in the study signed the consent for publication

Availability of data and material

The key raw data have been deposited into the Research Data Deposit (http://www.researchdata.org.cn), with the Approval and the datasets used in this study are publicly available.

Competing interests

The authors declare that they have no competing interests

Funding

This work was supported by the Natural Science Foundation of Guangdong Province of China (Grant Numbers. 2019A1515011601, 2019A1515010298)

Authors' contributions

JYW and HYL designed the study. WYZ and SSF drafted the manuscript, XQL and FFD collected and interpreted the data. WYZ carried out the statistical analysis. All authors read and approved the final manuscript.

Acknowledgements

Not applicable

\section{References}

1. Jemal A, Bray F, Center MM, Ferlay J, Ward E, Forman D. Global cancer statistics. CA Cancer J Clin 2011; 61(2): 69-90.

2. Chen W, Zheng R, Baade PD, et al. Cancer statistics in China, 2015. CA Cancer J Clin 2016; 66(2): 115-32. 
3. Gu X, Zheng R, Xia C, et al. Interactions between life expectancy and the incidence and mortality rates of cancer in China: a population-based cluster analysis. Cancer Commun (Lond) 2018; 38(1): 44.

4. HZ Z, GF J, HB S. Epidemiologic differences in esophageal cancer between Asian and Western populations. Chinese journal of cancer 2012; 31(6): 281-6.

5. Wang C, Wang J, Chen Z, Gao Y, He J. Immunohistochemical prognostic markers of esophageal squamous cell carcinoma: a systematic review. Chin J Cancer 2017; 36(1): 65.

6. Lagergren J, Smyth E, Cunningham D, Lagergren P. Oesophageal cancer. The Lancet 2017; 390(10110): 2383-96.

7. Chen J, Liu S, Pan J, et al. The pattern and prevalence of lymphatic spread in thoracic oesophageal squamous cell carcinoma. Eur J Cardiothorac Surg 2009; 36(3): 480-6.

8. Mu JW, Gao SG, Xue Q, et al. The impact of operative approaches on outcomes of middle and lower third esophageal squamous cell carcinoma. J Thorac Dis 2016; 8(12): 3588-95.

9. KC M. Total three-stage oesophagectomy for cancer of the oesophagus. The British journal of surgery 1976; 63(4): 259-62.

10. Li B, Xiang J, Zhang Y, et al. Comparison of Ivor-Lewis vs Sweet esophagectomy for esophageal squamous cell carcinoma: a randomized clinical trial. JAMA Surg 2015; 150(4): 292-8.

11. Okuyama M, Motoyama S, Suzuki H, Saito R, Maruyama K, Ogawa J. Hand-sewn cervical anastomosis versus stapled intrathoracic anastomosis after esophagectomy for middle or lower thoracic esophageal cancer: a prospective randomized controlled study. Surg Today 2007; 37(11): 947-52.

12. JS L, JY A, KD C, et al. Synchronous second primary cancers in patients with squamous esophageal cancer: clinical features and survival outcome. The Korean journal of internal medicine 2016; 31(2): 253-9.

13. Yao W, Meng Y, Lu M, et al. Impact of type 2 diabetes mellitus on short-term and long-term outcomes of patients with esophageal squamous cell cancer undergoing resection: a propensity score analysis. Cancer Commun (Lond) 2018; 38(1): 14.

14. R W, MJ W, JL Y, CW T. Upper gastrointestinal endoscopy detection of synchronous multiple primary cancers in esophagus and stomach: single center experience from china. Gastroenterology research and practice 2012; 2012(undefined): 432367.

15. Chen Z, Li S, He Z, Li G. Clinical analysis of 117 cases with synchronous multiple primary esophageal squamous cell carcinomas. The Korean Journal of Internal Medicine 2018.

16. Predrag Pesko MD, Srdjan Rakic, M.D., Ph.D., F.A.C.S., Miroslav Milicevic, M.D., Ph.D., Predrag Bulajic, M.D., and Zoran Gerzic, M.D., Ph.D. Prevalenceand Clinicopathologic Featuresof MultipleSquamousCell Carcinoma of the Esophagus. CANCER 1994; 73.

17. Wang Y, Zhu L, Xia W, Wang F. Anatomy of lymphatic drainage of the esophagus and lymph node metastasis of thoracic esophageal cancer; 2018. 
18. Li B, Hu H, Zhang Y, et al. Extended Right Thoracic Approach Compared With Limited Left Thoracic Approach for Patients With Middle and Lower Esophageal Squamous Cell Carcinoma: Three-year Survival of a Prospective, Randomized, Open-label Trial. Ann Surg 2018; 267(5): 826-32.

19. Shi H, Ma S, Zhao P, et al. Endoscopic ultrasonography for preoperative staging of esophageal carcinoma. Scand J Gastroenterol 2017; 52(10): 1052-6.

\section{Figures}


A

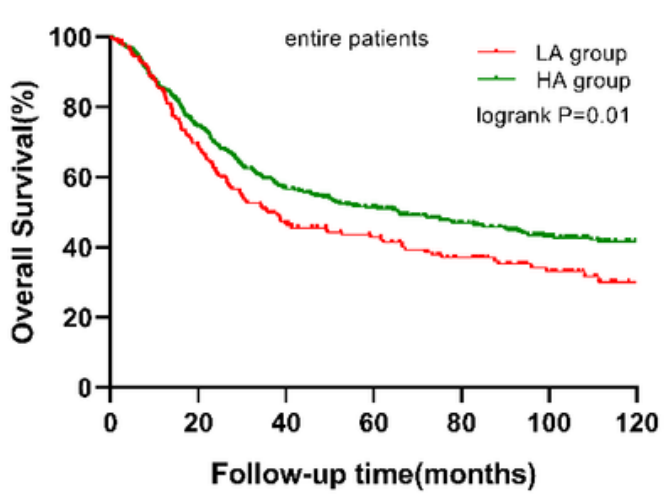

C

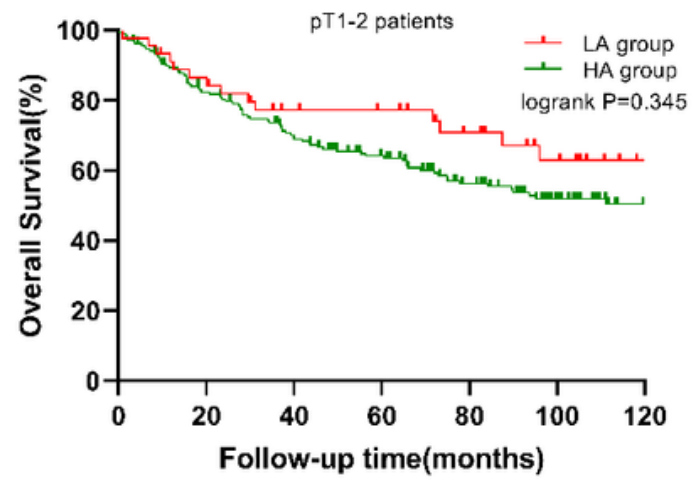

E

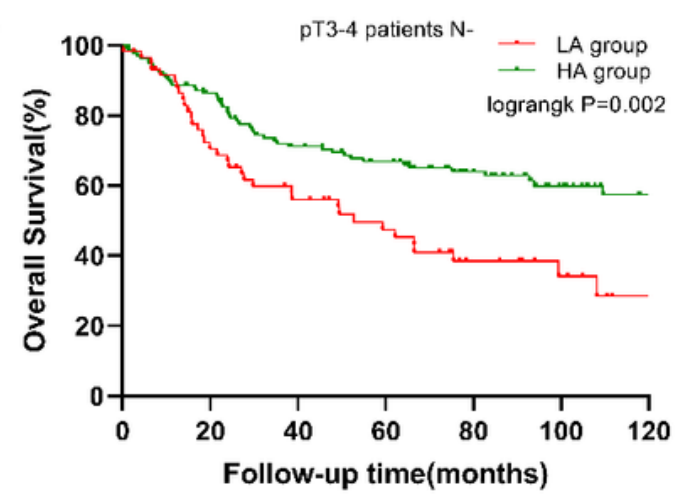

B

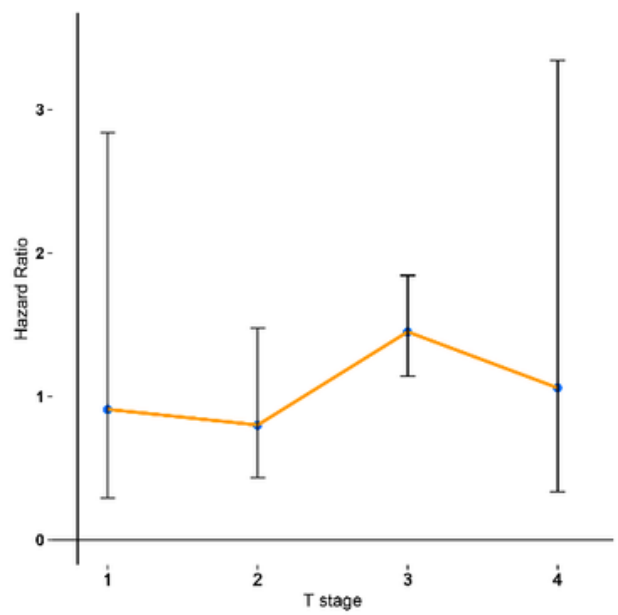

D

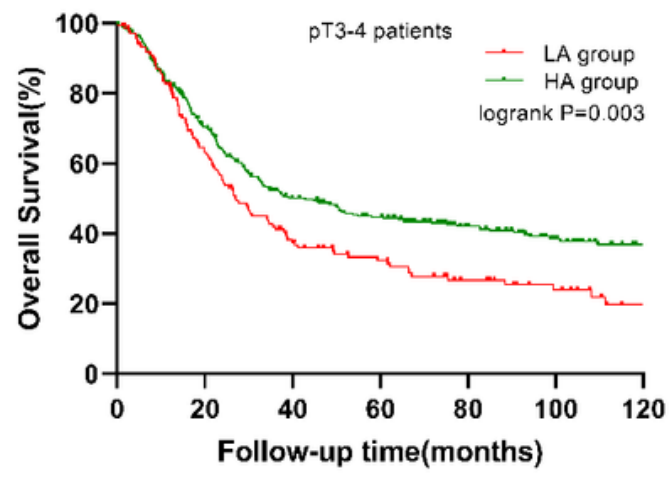

F

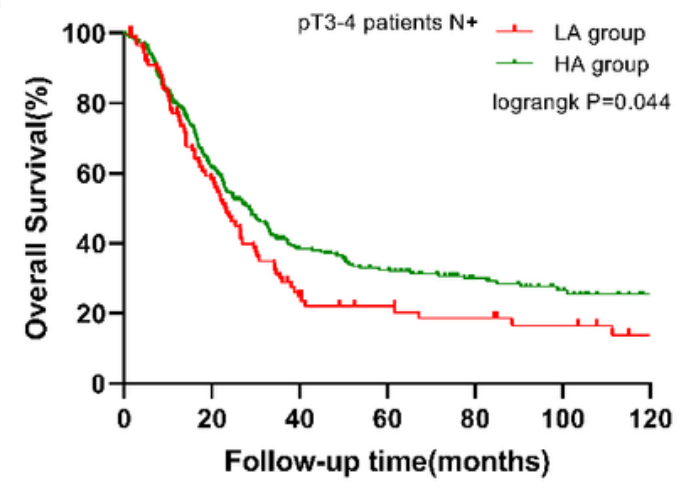

\section{Figure 1}

(A) overall survival for entire patients. (B) $95 \% \mathrm{Cl}$ of anastomosis location on each pT stage. (C) overall survival for pT1-2 patients. (D) overall survival for pT3-4 patients. (E) overall survival for pT3-4 N-patients. (F) overall survival for pT3-4 N+ patients. 

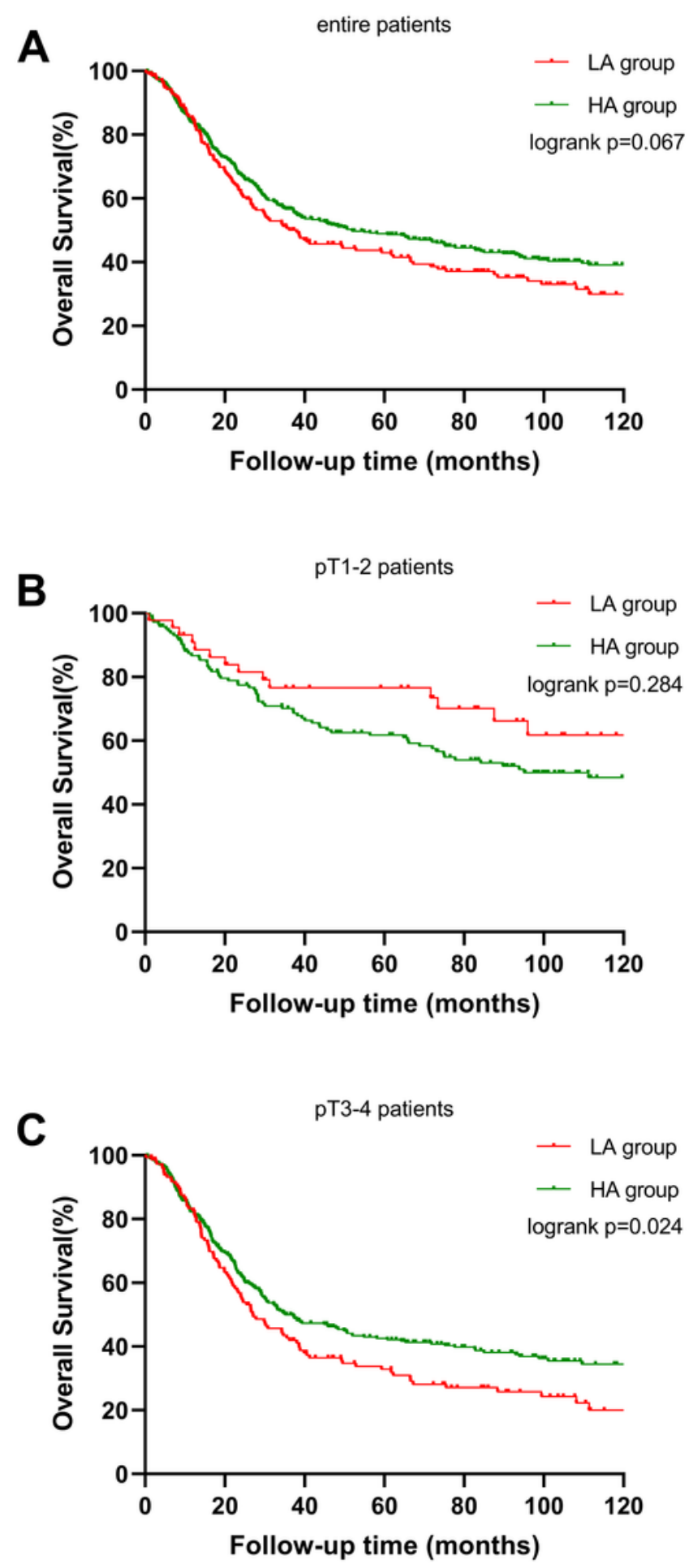

Figure 2

(A) overall survival for entire patients with Sweet approach. (B) overall survival for pT1-2 patients with Sweet approach. (C) overall survival for pT3-4 patients with Sweet approach. 